\title{
Polyphenols from Rheum Roots Inhibit Growth of Fungal and Oomycete Phytopathogens and Induce Plant Disease Resistance
}

\author{
Marit Gillmeister, ${ }^{1,}$ Silvia Ballert, ${ }^{1}$ Anja Raschke, ${ }^{2}$ Joerg Geistlinger, ${ }^{1}$ Kathrin Kabrodt, ${ }^{1}$ Helmut Baltruschat, ${ }^{1}$ \\ Holger B. Deising, ${ }^{2}$ and Ingo Schellenberg ${ }^{1}$ \\ ${ }^{1}$ Institute of Bioanalytical Sciences (IBAS), Anhalt University of Applied Sciences, 06406 Bernburg, Germany \\ ${ }^{2}$ Institute for Agricultural and Nutritional Sciences - Phytopathology and Plant Protection, Martin Luther University \\ Halle-Wittenberg, 06120 Halle (Saale), Germany
}

\begin{abstract}
A growing world population requires an increase in the quality and quantity of food production. However, field losses due to biotic stresses are currently estimated to be between 10 and $20 \%$ worldwide. The risk of resistance and strict pesticide legislation necessitate innovative agronomical practices to adequately protect crops in the future, such as the identification of new substances with novel modes of action. In the present study, liquid chromatography mass spectrometry was used to characterize Rheum rhabarbarum root extracts that were primarily composed of the stilbenes rhaponticin, desoxyrhaponticin, and resveratrol. Minor components were the flavonoids catechin, epicatechin gallate, and procyanidin B1. Specific polyphenolic mixtures inhibited mycelial growth of several phytopathogenic fungi and oomycetes. Foliar spray applications with fractions

containing stilbenes and flavonoids inhibited spore germination of powdery mildew in Hordeum vulgare with indications of synergistic interactions. Formulated extracts led to a significant reduction in the incidence of brown rust in Triticum aestivum under field conditions. Arabidopsis thaliana mutant and quantitative reverse-transcription polymerase chain reaction studies suggested that the stilbenes induce salicylic acid-mediated resistance. Thus, the identified substances of Rheum roots represent an excellent source of antifungal agents that can be used in horticulture and agriculture.

Keywords: cereals and grains, cultural and biological practices, disease management, antifungal compound, flavonoid, phytopathogenic fungi, plant defense, powdery mildew, Rheum, salicylic acid, stilbene.
\end{abstract}

An increasing demand for environmentally and socioeconomically acceptable alternatives to chemical fungicides has intensified research into new bio-based strategies in crop protection (Cáceres et al. 1991; Yoon et al. 2013). The need for new and innovative plant protection products is mainly driven by resistance management and legal registration. The fungicide market is dominated by compound classes with only a few distinct modes of action. Accordingly, about $70 \%$ of the global fungicide market is dominated by fungicides with a high to medium resistance risk (Leadbeater 2015). Phytopathogenic fungi are able to adapt to fungicidal modes of action through mutation, leading to a loss of fungicide efficacy (Aznar et al. 2015; Hahn 2014; Hollomon 2015). In addition to target site resistance (Kim et al. 2003; Lesemann et al. 2006; Sierotzki et al. 2000), pathogens have also acquired resistance mechanisms based on drug efflux transport and other detoxification methods (Ammar et al. 2013; Pedras and Ahiahonu 2005; Rupp et al. 2017; Yang et al. 2018). Furthermore, the number of synthetic fungicides available on the market is decreasing, because many cannot be reregistered due to changing crop protection legislation (Chapman 2014; Deising et al. 2017; Thompson et al. 2008).

In order to control economically important plant pathogens, alternatives have been developed based on various plant species that harbor diverging plant protective ingredients (Chen and Dai 2014;

${ }^{\dagger}$ Corresponding author: M. Gillmeister; E-mail: marit.gillmeister@hs-anhalt.de

Funding: The research leading to these results was funded by the Bundesministerium für Bildung und Forschung under the funding code 03WKP32A

*The $\boldsymbol{e}$-Xtra logo stands for "electronic extra" and indicates that three supplementary figures and three supplementary tables are published online.

The author(s) declare no conflict of interest.

Accepted for publication 10 February 2019.

() 2019 The American Phytopathological Society
Copping and Menn 2000). Some of these act via the natural plant defense system (i.e., systemic acquired resistance [SAR]). Mechanisms that activate SAR were examined in detail at the biochemical and molecular levels in Cucumis sativus (cucumber), Nicotiana tabacum (tobacco), and Arabidopsis thaliana (Lawton et al. 1993; Shine et al. 2019; Ward et al. 1991). SAR-related host defense responses included transcriptional induction of genes that encode pathogenesisrelated (PR) proteins, formation of reactive oxygen species, and callose deposition to strengthen the cell wall (Conrath 2006; Schneider et al. 1996). The importance of novel mode-of-action chemicals capable of activating SAR for unique crop protection strategies has been fully acknowledged (Dong 1998; Gozzo and Faoro 2013; Ryals et al. 1996), and a considerable number of natural and synthetic substances have been evaluated with regard to their ability to induce resistance in plants (Kessmann et al. 1994). Surprisingly, even fungicides act as priming agents and, thus, exhibit direct and indirect modes of protecting plants against diseases. For instance, a strobilurin fungicide promotes resistance of tobacco against Tobacco mosaic virus and Pseudomonas syringae pv. tabaci by priming the plants for faster accumulation of PR-1 proteins (Herms et al. 2002). Furthermore, synthetic benzothiadiazole (BTH) shows SAR-inducing effects in powdery mildew-infected Triticum aestivum (wheat) (Görlach et al. 1996). Likewise, chemical derivatives mimicking the resistance-inducing activity of salicylic acid (SA), such as 2,6-dichloroisonicotinic acid, have also been shown to induce SAR (Kauss et al. 1992; Malamy and Klessig 1992; Morris et al. 1998). Protective plant activator Bion has been introduced to the market as an efficient alternative to conventional agents and is well tolerated by plants. However, farmers prefer reliable curative commercial fungicides and the Bion agent BTH has not been widely used (Conrath et al. 2015). Therefore, the main task for successful antifungal strategies is to develop substances with a low risk of resistance (i.e., direct antifungal activity and priming capacity), which combine sustainability, broad-spectrum efficacy, and low toxicity in humans, animals, host plants, and ecosystems (Beckers and Conrath 2007; Chollet et al. 2014).

For example, root extracts of Rumex crispus reduce disease symptoms of powdery mildews in Hordeum vulgare (barley) and 
cucumber as effectively as the synthetic fungicide fenarimol (Kim et al. 2004). Substances isolated from $R$. crispus also show fungicidal activity against Blumeria graminis f. sp. hordei and have been identified as chrysophanol, parietin, and nepodin (Choi et al. 2004). A leaf extract from Reynoutria sachalinensis has been commercialized (Milsana) due to its effectiveness in combating powdery mildew in cucumber. Intriguingly, the latter studies have shown that the active ingredients in $R$. sachalinensis (mainly anthraquinon physcion) do not primarily exhibit antifungal properties but, rather, induce resistance pathways in plants (Herger and Klingauf 1990; KonstantinidouDoltsinis and Schmitt 1998).

Due to their large quantities of complex polyphenolic substances, the roots of approximately 60 species of the genus Rheum (rhubarb) may prove to be a promising source of novel plant protection compounds (Kuhl and DeBoer 2008). Bioactive phenolic compounds have been identified in Rheum roots, including stilbenes, flavonoid-type catechins, and anthraquinones (Ye et al. 2007). Flavonoids and related polyphenols are known to inhibit spore germination of fungal phytopathogens, as exhibited in the isoflavonoid phytoalexin maackiain in Cicer bijugum (wild chickpea), by interfering with conidial germination of Botrytis cinerea (Harborne and Williams 2000; Stevenson and Haware 1999). The stilbene phytoalexin resveratrol (RES) also stimulates plant defense responses (Adrian et al. 1997; Gonzalez Ureña et al. 2003; Langcake and Pryce 1976; Pezet et al. 2004a,b; Pociecha et al. 2014). Increased resistance to $B$. cinerea in vivo, mediated by fungitoxic RES, was due to stilbene synthase genes transferred to tobacco for phytoalexin biosynthesis (Hain et al. 1993). Stilbenes have also been generally shown to inhibit spore germination and hyphal growth (Kumar and Nambisan 2014). Extracts of anthraquinones from plant species such as Rheum emodi or R. officinale, including physcion or rhein, have been described as potent antifungal agents (Agarwal et al. 2000; Yang et al. 2009); however they may no longer be used as commercial pesticides in the European Union (EU; 2008/986/EC).

The aim of the current study was to investigate the impact of anthraquinone-depleted root extracts from $R$. rhabarbarum against fungal and oomycete plant diseases, with a strong focus on biotrophic B. graminis f. sp. hordei. The assays ranged from mycelial growth tests to large-scale field trials, combined with greenhouse studies on the antifungal and resistance-inducing properties of the obtained root extracts. The chemical characterization of Rheum bioactive secondary metabolites (i.e., flavan-3-ols and stilbenes) found epicatechin gallate (ECG), RES, and other related compounds to be highly efficient in controlling plant diseases. They featured direct antifungal properties and were found to induce immune responses in host plants.

\section{Materials and Methods}

Extraction and fractionation of Rheum root compounds. R. rhabarbarum L. 'The Sutton' $\left(\right.$ Rrha $\left._{\mathrm{E}}\right)$ was cultivated at Anhalt University in Bernburg-Strenzfeld, Germany $\left(51^{\circ} 82^{\prime} \mathrm{N}, 11^{\circ} 70^{\prime} \mathrm{E}, 80 \mathrm{~m}\right.$ above sea level) on a loess chernozem ( $\mathrm{pH} 7.0$ to 7.4), and harvested after about 7 years of cultivation. After undergoing cleaning and drying $\left(60^{\circ} \mathrm{C}\right)$, its roots were extracted using a multistep laboratory method consisting of solid/liquid and liquid/liquid extraction with different polar solvents (methanol and ethyl acetate) followed by lyophilization (Baltruschat et al. 2013). Unformulated polyphenolenriched ethyl acetate phases and, for field trials, a 30\% (wt/vol) formulated ethyl acetate phase of Rrha (HELM AG, Hamburg, Germany) were used in further investigations. Crude extracts from R. officinale BAILL. Roff $_{\mathrm{E} 39} /$ Roff $_{\mathrm{E} 18}$; accession number RHEUM 39/18; IPK, Gatersleben, Germany) and one from Rumex obtusifolius L. (RUo ; accession number RUM 48; IPK) were obtained accordingly (Supplementary Table S1). Roff ${ }_{\mathrm{E} 39}, \mathrm{Roff}_{\mathrm{E} 18}$, and $\mathrm{RUo}_{\mathrm{E}}$ were applied in mycelial growth tests and barley leaf segment assays (LSAs). Aliquots of the four mixed phases (Rrha $, \operatorname{Roff}_{\mathrm{E} 39}, \operatorname{Roff}_{\mathrm{E} 18}$, and RUo $\left.\mathrm{O}_{\mathrm{E}}\right)$ were used for liquid chromatography mass spectrometry (LC-MS) analysis and for testing.

Fractionation of the Rrha $a_{E}$ mixed phase (crude extract) was performed using a preparative-scale high-performance liquid chromatography (HPLC) system (Varian Pro/PrepStar; Agilent
Technologies, Waldbronn, Germany), equipped with ZORBAX Eclipse XDB-C18 (30.0 by $250 \mathrm{~mm}, 5 \mu \mathrm{m})$ and Prep Guard-C18 $(21.2 \mathrm{~mm}, 10 \mu \mathrm{m})$ columns. The mobile phase consisted of $0.5 \%$ (vol/vol) acetic acid and methanol (gradient elution of 23 to $60 \%$ methanol for the first $40 \mathrm{~min}$, then rising to $100 \%$ for $7 \mathrm{~min}$, and held at $100 \%$ methanol for another $8 \mathrm{~min}$ ). Run time was $65 \mathrm{~min}$ at a flow rate of $34 \mathrm{ml} \mathrm{min}^{-1}, 30^{\circ} \mathrm{C}$, and $280 \mathrm{~nm}$ detection wavelength (injection volume $\geq 7.5 \mathrm{ml}$ ). Per fraction, volumes of 54 identical HPLC runs were collected, mixed, evaporated, and freeze dried. Aliquots of the Rrha $\mathrm{E}_{\mathrm{E}}$ fractions were used for LC-MS analysis and for testing.

All freeze-dried extracts and fractions that were used in subsequent experiments were dissolved in distilled water prior to use. Extracts are, in principle, available upon request but, due to the laboratory production methods, a case-by-case decision has to be made for specific requests.

Plant material, phytopathogens, and growth conditions. Rrha was tested with two in vivo model systems including biotrophic plant-fungus pathosystems: (i) H. vulgare L. 'Lawina'-Blumeria graminis (DC.) E. O. Speer f. sp. hordei and (ii) A. thaliana (L.) Heynh. acc. Col-8 or deficiency mutants-Erysiphe cruciferarum Opiz ex L. Junell. Arabidopsis mutants eds5-1, eds8, ein2-1, jar1-1, MYB51, npr1-1, npr1-3, pad2-1, and pad4-1 were used for mutant screening. The barley plants used in the LSAs and histochemical studies were cultivated in a greenhouse in type $\mathrm{T}$ Fruhstorfer potting soil (Hawita-Group, Vechta, Germany) for 2 to 3 weeks at $19.5^{\circ} \mathrm{C}$ and $51.8 \%$ relative humidity. Arabidopsis plants, used in the mutant screening and transcript abundance analyses, were grown in a climate chamber for 8 weeks under a light regime of $12 \mathrm{~h}$ of light and $12 \mathrm{~h}$ of darkness with $2,080 \pm 6 \%$ lux light intensity at $20^{\circ} \mathrm{C}$ and $81 \%$ relative humidity. B. graminis f. sp. horde $i$ and $E$. cruciferarum isolates were maintained in climate chambers (light regime of $12 \mathrm{~h}$ of light and $12 \mathrm{~h}$ of darkness with $7,000 \pm 6$ and $34,450 \pm 6 \%$ lux light intensity, 20 and $18^{\circ} \mathrm{C}$, and 75 to $82 \%$ relative humidity) by infecting plants every 1 to 2 weeks.

In vitro mycelial growth tests were conducted with necrotrophic and hemibiotrophic fungi and oomycetes. Alternaria brassicicola (Schwein.) Wiltshire, Fusarium culmorum (Wm. G. Sm.) Sacc., F. oxysporum f. sp. lycopersici W. C. Snyder \& H. N. Hansen, and Magnaporthe oryzae B.C. Couch were cultivated on potato dextrose medium; Phytophthora capsici Leonian isolates (LT15341, LT1232, and 2131103) on V8 juice medium; and Venturia inaequalis (Cooke) G. Winter on a malt extract glucose medium at $22^{\circ} \mathrm{C}$ for 1 to 3 weeks. Field trials were performed with the winter wheat (T. aestivum L.) cultivars Pamier and Julie E, grown on an experimental field site in Bernburg-Strenzfeld, Germany (annual average temperature of 9.4 to $11.0^{\circ} \mathrm{C}$, average relative humidity of 76 to $80 \%$ ). The trial was repeated in two seasons (2015 and 2017). Plant material and phytopathogens used for in vitro tests, in vivo assays, and field trials are listed in Supplementary Table S2.

Plant treatments. Leaf treatments for in vivo assays were conducted by spraying plants with a membrane-vacuum pump with glass sprayer (model N022 AN.18; KNF Neuberger GmbH, Freiburg, Germany and Hofmann Glastechnik $\mathrm{GmbH}$, Staudt, Germany) using $1 \mathrm{bar}$ of pressure $48 \mathrm{~h}$ before pathogen inoculation. Each treatment group was sprayed with the same spray volume. All control plants used in the in vivo assays were treated with distilled water. The barley plants used in the LSAs and histochemical studies were treated with concentrations ranging from 8 to 500 parts per million (ppm; distilled water-based solutions). Arabidopsis plants used in the mutant screening and transcript abundance analyses were treated with extract concentrations of $0.5 \%(\mathrm{wt} / \mathrm{vol})$ and $0.1 \%(\mathrm{wt} / \mathrm{vol})$, respectively. Wheat plants intended for the field trials were treated with extract or fungicide dosages of up to $800 \mathrm{~g} \mathrm{ha}^{-1}$. Fungicides used in the field trials were purchased from BASF SE, Ludwigshafen, Germany. For controls, an equal volume of the plant extract solvent (distilled water) was sprayed. BREAK-THRU S 240 (B-T S 240, polyether trisiloxane; Evonik Industries AG, Essen, Germany) was deployed as a $0.1 \%(\mathrm{vol} / \mathrm{vol})$ adjuvant for leaf treatments with extracts, fractions, or standard substances and treatments with water (controls). Plants for transcript abundance analyses were not treated with adjuvants. In field trials, B-T S 240 was used in dosages of $300 \mathrm{ml} \mathrm{ha}^{-1}$. Two 
treatments were applied with flat spray nozzles at developmental stages DS 33-37 (flag leaf) and DS 51-61 (ear emergence) in randomized field plots. Dip inoculation of leaves with fungal conidia for barley and Arabidopsis LSAs (Hückelhoven et al. 1999; Johansson et al. 2014) led to an average of 1.1 and 1.2 conidia per $\mathrm{mm}^{2}$ leaf area respectively, while a higher conidial density $\left(3.4\right.$ conidia per $\left.\mathrm{mm}^{2}\right)$ was applied on leaves used in the quantitative reverse-transcription polymerase chain reaction (qRT-PCR) analyses.

LSAs, histochemical studies, mycelial growth tests, and field trials. The barley LSAs were evaluated by visually estimating the number of $B$. graminis $\mathrm{f}$. sp. hordei pustules on 7-cm-long leaf segments ( $\geq$ two biological and $\geq$ nine technical replicates). Synergistic effects in barley LSAs were calculated according to Colby (1967). LSAs for Arabidopsis (mutant screening) were evaluated by visually estimating the infestation intensity ( $\geq 3$ biological and 16 technical replicates). Disease severity was recorded in percentage of mycelium-covered leaf surface for both assays.

For the histochemical observations, infected leaves were stained with 3,3'-diaminobenzidine or acetic ink as described by Hückelhoven and Kogel (1998) and Hückelhoven et al. (1999). Conidial germination rates and interaction phenotypes were recorded according to Koga et al. (1990) by evaluating 100 interaction types per leaf segment (two biological and five technical replicates).

In vitro mycelial growth tests were performed by incorporating the extract solutions into the respective nutrient medium (1,000 ppm final extract concentration). For controls, an equal volume of the plant extract solvent (distilled water) was added to the nutrient medium. Test plates were inoculated with a mycelium agar plug measuring $0.28 \mathrm{~cm}^{2}$ by placing the mycelial disk centrally on the plate. After incubation at $22^{\circ} \mathrm{C}$ for 1 to 3 weeks, the diameter of the grown mycelium was measured crosswise and compared with the control without the extract addition ( $\geq$ three biological or technical replicates).

For field trials, the experimental field represented a randomized plot design with four replicates per treatment group of about $10 \mathrm{~m}^{2}$ each (seed rate: approximately 350 seeds $/ \mathrm{m}^{2}$ ). The severity of the infection with brown rust was evaluated by sampling a representative number of flag leaves ( $\geq 150$ technical replicates) from several locations inside the test field. Disease symptoms were examined using scales ranging from 0 to $100 \%$ (pustules per leaf area).

DNA-microarray and qRT-PCR analyses. For each treatment, three Arabidopsis leaves were sampled from three individual plants at 3 and $9 \mathrm{~h}$ after treatment (HAT) for the DNA-microarray analyses, and at 3 and 9 HAT or 8 and $16 \mathrm{~h}$ after inoculation (HAI) for the qRT-PCR analyses (two independent tests each). DNA-microarray experiments were performed using two biological and one technical replicates (mixed leaf sample). qRT-PCR experiments were performed using two biological and $\geq$ three to five technical replicates. mRNA isolation (RNeasy Plant Mini Kit; QIAGEN GmbH, Hilden, Germany) and cDNA synthesis (SuperScript First-Strand Synthesis System; Life Technologies GmbH, Darmstadt, Germany) were conducted in accordance with the manufacturer's instructions. Microarray analyses were performed using a processing kit (Affymetrix GeneChip [AraGene 1.0 ST Array]; Ambion WT Expression Kit; Thermo Fisher Scientific, Darmstadt, Germany). Sample processing and Affymetrix microarray hybridization were carried out at a genomics core facility: Center of Excellence for Fluorescent Bioanalytics (KFB, University of Regensburg, Germany). The qRT-PCR analyses focused on $P R 1, P R 2$, and $P R 5$ using a QuantiTect SYBR Green PCR Kit (QIAGEN GmbH) and primers specific to the investigated $P R$ genes (primer pairs $A t$-PR1, $A t$-PR2, and $A t$-PR5) (Lindermayr et al. 2010). Ubiquitin and actin were examined for suitability as reference genes. At-Actin (primer pair At-Act1) (Hermann et al. 2013) repeatedly failed to provide reproducible cycle threshold $(\mathrm{Ct})$ values with a high deviation over $0.5 \mathrm{Ct}$. Therefore, the reference gene At-Ubiquitin (primer pair At-Ubi) (Shi et al. 2013) was used for normalization. Primers were synthesized by Metabion International AG, Planegg/Steinkirchen, Germany. Relative transcript abundances were quantified using the $\Delta \Delta \mathrm{Ct}$ method (Livak and Schmittgen 2001).

High-performance LC-MS analyses. Three methods were applied to qualitatively and quantitatively evaluate extract ingredients: (i) the LC-diode array detection (DAD) method (peak area determination), (ii) the full-scan method for substance identification (semiquantification), and (iii) the quantification method using multiple reaction monitoring, information-dependent acquisition, enhanced product ion (MRM-IDA-EPI) and library matching.

The HPLC method was performed using a Synergi Hydro-RP $80 \AA$ column ( 250 by $2.0 \mathrm{~mm}, 4 \mu \mathrm{m}$; Phenomenex Ltd., Aschaffenburg, Germany) with $0.1 \%$ (vol/vol) formic acid in water and $100 \%$ methanol as mobile phase (gradient elution from 0 to $10 \%$ methanol for the first $5 \mathrm{~min}$, then increasing to $100 \%$ after $57.6 \mathrm{~min}$, and held at $100 \%$ methanol for another $7.4 \mathrm{~min}$ ), $80.1 \mathrm{~min}$ total run time, $0.25 \mathrm{ml} \mathrm{min}{ }^{-1}$ flow rate, 190 to $950 \mathrm{~nm}$ DAD detection spectrum, and $10 \mu \mathrm{l}$ injection volume, with 4 and $40^{\circ} \mathrm{C}$ auto-sampler and column temperature, respectively. The combined full-scan method (quadrupole Q1 scan method) was performed using a 4000 QTRAP mass spectrometer from Sciex GmbH, Darmstadt, Germany, which provided a total ion current (source: electrospray ionization, polarity: negative, duration: $80 \mathrm{~min}$, full-scan range: 100 to $1,300 \mathrm{Da}$, time per cycle: $3 \mathrm{~s}$ ).

The MRM experiment was used in the quantitative analysis, which also served as a survey scan for the EPI. External calibration was obtained by applying 16 standard substances typical for Rheum spp. at concentration levels ranging from 5 to $1,000 \mathrm{ng} \mathrm{ml}^{-1}$, with correlation coefficients $r^{2}>0.99$. The five flavan-3-ols- $(+)$ catechin, (-)epicatechin, (-)epigallocatechin, ECG, and (-)epigallocatechin gallate-as well as three procyanidin standards (procyanidin B1, B2, and C1) and the standard substances 3,4',5-trihydroxystilbene3-O- $\beta$-D-glucoside/-glucopyranoside (piceid), rhaponticin, and RES were purchased from Extrasynthese, Genay, France. The standard substance piceatannol was purchased from BIOTREND Chemikalien $\mathrm{GmbH}$, Wangen, Switzerland; desoxyrhaponticin from SigmaAldrich Chemie GmbH, Taufkirchen, Germany; and three phenolic acids (p-coumaric acid, ferulic acid, and chlorogenic acid) from Carl Roth GmbH + Co. KG, Karlsruhe, Germany. The EPI scan (scan rate: $1,000 \mathrm{Da} \mathrm{s}^{-1}$ ) used for substance confirmation was programmed and added through IDA criteria with dynamic background subtraction of the survey scan. Samples were measured in duplicate.

Statistical analyses. Statistical analyses were conducted using SigmaPlot (version 13.0; Systat Software, Inc., San José, CA, U.S.A.) to determine variances between different treatment groups (one-way analysis of variance and Dunnett's and Dunn's methods). Whereas the Dunnett's test was used for comparisons between experimental treatment groups and a single control group, the Dunn's test served as the statistical method for pair-by-pair comparisons and comparisons versus a control group. The differences in the mean and median values of $P<$ 0.05 between treatment groups were set as the significance threshold. The $t$ test (Mann-Whitney rank sum test) was applied to comparisons comprising only two groups. Technical and biological replicates varied depending on the experimental design (see Materials and Methods)

\section{Results}

R. rhabarbarum extract Rrha $_{\mathrm{E}}$ inhibits mycelial growth of plant-pathogenic fungi and oomycetes. Infection assays were used to analyze the effect of Rheum root extracts in controlling plant diseases. Barley leaves were treated with extracts from $R$. rhabarbarum (Rrha $\left.\mathrm{E}_{\mathrm{E}}\right)$, R. officinale ( $\left.\operatorname{Roff}_{\mathrm{E}}\right)$, and $R$. obtusifolius $\left(\mathrm{RUo}_{\mathrm{E}}\right)$, dissolved in $0.1 \%$ B-T S 240 , along with $0.1 \%$ B-T S 240 water controls. For LSAs, the pretreated leaves were excised, inoculated with B. graminis f. sp. hordei at about 1.1 conidia $/ \mathrm{mm}^{2}$, and incubated until approximately $90 \%$ of the leaf surface of the control plants was covered with mycelium. The inhibitory effect of all extracts on $B$. graminis $\mathrm{f}$. sp. horde $i$ was macroscopically evident and statistically significant (Fig. 1A and B). Intriguingly, at dosages of 125 and $250 \mathrm{ppm}$, Rrha $\mathrm{E}$ completely inhibited fungal growth (Dunn's method versus control group, $P<0.001)$. Roff $_{\mathrm{E}}$ and $\mathrm{RUO}_{\mathrm{E}}$ reduced $B$. graminis f. sp. hordei disease severity in a statistically significant dosedependent manner by an average of 15 to $5 \%$ and 4 to $1 \%$, respectively (Fig. 1A).

The inhibition of the $B$. graminis f. sp. hordei infection by Rrha $\mathrm{E}_{\mathrm{E}}$ in LSAs was analyzed in more detail through microscopy by using 



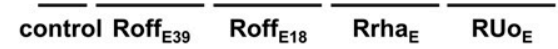
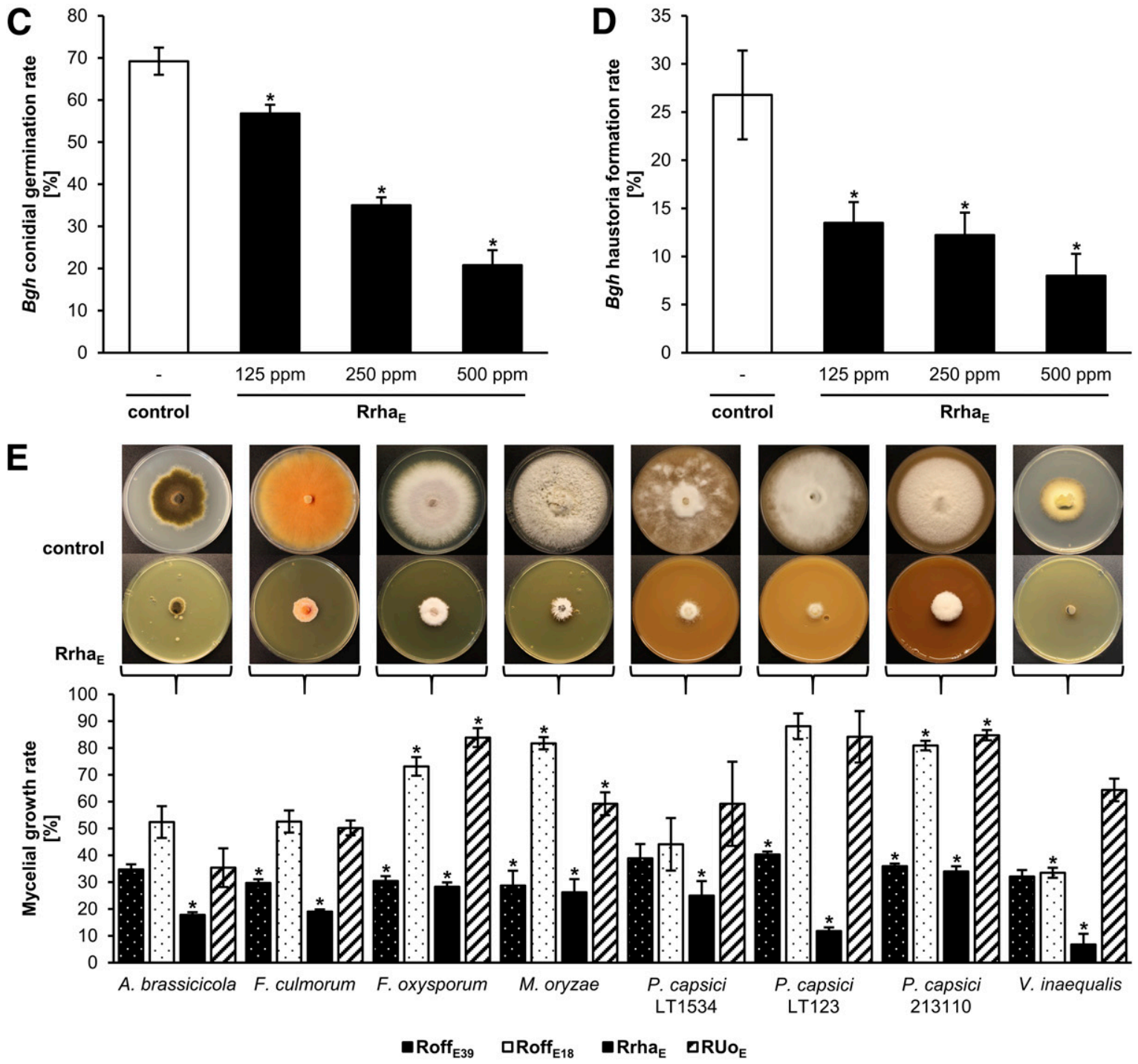

Fig. 1. Antifungal effects of Rheum and Rumex root extracts. A and B, Blumeria graminisf. sp. hordei (Bgh) pustule formation (pustules/leaf area) 2 weeks after Hordeum vulgare 'Lawina' infection. Three-week-old plants were sprayed with different Rheum (Rheum officinale [Roff $E$ ] and $R$. rhabarbarum [Rrha $]$ ) and Rumex (Rumex obtusifolius [RUo $]$ ) root extracts followed by inoculation with $B$. graminis f. sp. hordei at $48 \mathrm{~h}$ after treatment (HAT). For controls, an equal volume of the solvent was sprayed. Significant differences in disease severity assessed using Dunn's method versus control group $(P<0.001)$ are marked with an asterisk $(A)$. Graph bars represent mean values of $\geq 2$ biological and 15 technical replicates, error bars represent standard error of the mean (SEM). Images show representative symptom developments (B). C, Conidial germination rate and $\mathbf{D}$, haustoria formation rate of $B$. graminis $\mathrm{f}$. sp. hordei 2 days after $H$. vulgare 'Lawina' infection. Two-week-old plants were sprayed with Rrha $a_{E}$ followed by inoculation with B. graminis f. sp. hordei at 48 HAT. For controls, an equal volume of the solvent was sprayed. Significant differences in $B$. graminis f. sp. hordei germination rate assessed using Dunnett's method $(P \leq 0.009)$ and haustoria rate using $t$ test $(P \leq 0.031)$ are marked with an asterisk. Graph bars represent mean values of two biological and five technical replicates; error bars represent SEM. E, Mycelial growth rates of hemibiotrophic and necrotrophic fungi and oomycetes after 1 week of incubation. Images show mycelial growth on solvent-supplemented (control) and RrhaEsupplemented potato dextrose (Alternaria brassicicola, Fusarium spp., and Magnaporthe oryzae), V8 juice (Phytophthora capsici), or malt extract glucose (Venturia inaequalis) media. Graph values were measured as average diameter (in centimeters) and given as relative growth versus control (percentage). Growth rates of $M$. oryzae and $V$. inaequalis were determined after 2 and 3 weeks, respectively. Plant pathogens were grown on nutrient agar supplemented with the extracts as described (1,000 ppm). For controls, an equal volume of the solvent was added to the nutrient medium. Significant differences in mycelial growth assessed using Dunnett's method or Dunn's method versus control group $(P \leq$ 0.032 ) are marked with an asterisk. Graph bars represent mean values of $\geq$ three biological or technical replicates, error bars represent SEM. 
highly susceptible Lawina barley. In concordance with the extract treatments, the number of conidia that formed appressoria was significantly lower (Dunnett's method, $P \leq 0.009$ ) depending on the dosage (Fig. 1C). Correspondingly, haustoria were formed at significantly lower rates ( $t$ test, $P \leq 0.031)$ compared with the water-treated controls (Fig. 1D).

It is conceivable that assays using obligate biotrophs are unable to differentiate between direct antifungal activity and resistanceinducing effects in the host plant. Therefore, only the effects of the extracts on mycelial growth of economically relevant hemibiotrophs and necrotrophs could be examined in axenic cultures. Whereas $A$. brassicicola, which causes leaf spots, and the three $P$. capsici isolates exhibited retarded growth, with growth rates of 18 to $35 \%$ and 12 to $40 \%$, respectively, compared with the water controls, the hemibiotrophic rice blast fungus $M$. oryzae showed a significantly reduction in growth (26 to $29 \%$ relative growth versus control) when treated with Rrha $_{\mathrm{E}}$ and Roff $\mathrm{E}_{9}$ (Fig. 1E). Due to the Rrha $\mathrm{E}_{\mathrm{E}}$ treatment, the apple scab fungus $V$. inaequalis exhibited significantly reduced growth rates, with inhibition of up to $100 \%$ (Dunnett's method, $P<$ $0.001)$. Rrha $\mathrm{E}$ was also effective against $F$. culmorum and $F$. oxysporum f. sp. lycopersici, even at lower dosages of 250 to $63 \mathrm{ppm}$ (growth rates of 34 and $41 \%$, respectively, versus control; data not shown). Although Rrha $\mathrm{E}$ and $\operatorname{Roff}_{\mathrm{E} 39}$ provided moderate to complete inhibition of all tested plant pathogens, Roff $\mathrm{E}_{18}$ and $\mathrm{RUo}_{\mathrm{E}}$ were effective in only two of eight isolates with reduced impact (30 to $50 \%$ relative growth versus control; Fig. 1E).

Stilbenes are the major compounds in the $R$. rhabarbarum extract $\mathbf{R r h a}_{\mathbf{E}}$. The chemical composition of the extracts was determined by LC-MS. Rrha ${ }_{E}$ was primarily composed of the stilbene derivates rhaponticin (RHA), desoxyrhaponticin (DRHA), and RES (Fig. 2A). Minor components were the flavonoids catechin, ECG, and procyanidin B1 (PRO B1) (Fig. 2B). These compounds were purified and concentrated as defined fractions using preparative HPLC. RES was highly concentrated in fraction 5 (Fig. 2C and E), while RHA appeared in fraction 4 and DRHA in fraction 7 (Fig. 2C and F). ECG was primarily found in fractions 2 to 4 (Fig. 2D and G). Other stilbenes such as piceatannol glucopyranoside and rhapontigenin in $\mathrm{Rrha}_{\mathrm{E}}$ are presented in Supplementary Fig. S1. Compared with the other crude extracts (Supplementary Fig. S2), the quantitative distribution of compounds identified in Rrha ${ }_{E}$ was similar, with only minor differences from $\operatorname{Roff}_{\mathrm{E} 39}$. In contrast to $\mathrm{Rrha}_{\mathrm{E}}$ and $\operatorname{Roff}_{\mathrm{E} 39}$, the composition of ingredients in $\mathrm{Roff}_{\mathrm{E} 18}$ and $\mathrm{RUo}_{\mathrm{E}}$ differed remarkably. Large amounts of catechin (approximately 25-fold) and an enrichment of ECG (8-fold) were found in these extracts. Additionally, the content of PRO B1 was seven to eight times higher in Roff $\mathrm{E}_{\mathrm{E} 18}$ and $\mathrm{RUO}_{\mathrm{E}}$ than in the other analyzed extracts.

Polyphenolic compounds from stilbenes and flavonoids mediate $B$. graminis f. sp. hordei control. To determine the active components in $\mathrm{Rrha}_{\mathrm{E}}$ that suppress $B$. graminis f. sp. hordei infection, barley LSAs were conducted with $B$. graminis f. sp. hordei and distinct fractions of Rrha $\mathrm{E}_{\mathrm{E}}$. Flavonoids from fractions 1 and 2 as well as stilbenes from fraction 5 showed strong activity in reducing mildew disease, with only a 2 to $5 \%$ disease severity compared with the water-treated controls (Fig. 3A). Other fractions exhibited moderate to low activity (Fig. 3A). Fractions 2 and 5, as well as the major flavan-3-ol and stilbene in these fractions (i.e., ECG and RES by the use of standard substances), significantly reduced conidial germination rates of $B$. graminis f. sp. hordei (Dunnett's method, $P \leq$ 0.020 ; Fig. 3B). Haustoria formation was also significantly inhibited in leaf segments ( $t$ test versus control, $P=0.011$ or 0.031 ) treated with fraction 5 (containing the main compound RES) and pure standard ECG (Fig. 3C).

To investigate possible synergistic effects, barley LSAs were performed with commercially available ECG and RES as well as PRO B2 and RHA, and protectively applied individually and in combination. ECG and RES application showed significantly less disease than control application when applied in combination (100\% B. graminis f. sp. hordei efficiency) (Fig. 3D). B. graminis f. sp. hordei symptom development was not significantly different from control infection (Dunn's method versus control group, $P \geq 0.142$ ) in the case of single-dose applications of $8 \mathrm{ppm}$. Combined treatments resulted in significant (Dunn's method versus control group, $P<$ 0.001 ) and considerably better mildew control than the single applications (Fig. 3D). These inhibitory effects were not additional but synergistic (100\% observed versus $70 \%$ calculated B. graminis $\mathrm{f}$. sp. hordei efficiency with the use of $8+8 \mathrm{ppm}$ ). Similar effects were observed when plants were pretreated with PRO B2 and RHA (Fig. 3E).

$R$. rhabarbarum extract Rrha $_{\mathrm{E}}$ exhibited strong efficacy in field tests. Due to inhibition of spore germination and mycelial growth after Rrha ${ }_{E}$ application and because of its plant-protecting potential, Rrha ${ }_{E}$ was applied in a field trial with Pamier winter wheat in 2015. Flag leaves of 700 individual plants per treatment group were rated for disease incidence. Field sampling revealed severe leaf rust (Puccinia triticina) disease pressure. When formulated Rrha ( Rrha $_{\mathrm{Ef}}$ ) and fenpropimorph (Corbel) were used (Fig. 4A), average growth rates of brown rust pustules converged depending on Rrha dosage, with disease severities of 18 to $13 \%$ (Dunnett's method, $P<$ $0.001 ; 200$ versus $800 \mathrm{~g} \mathrm{ha}^{-1} ; t$ test, $\left.P<0.001\right)$. Corbel reduced brown rust infestation by an average of $76 \%$ (Dunnett's method, $P<0.001$ ). Approximately $94 \%$ pustule inhibition was achieved through combined treatments with Rrha ${ }_{\mathrm{Ef}}$ and Corbel (Dunnett's method, $P<$ 0.001 ). The field experiment was independently repeated with Julie E winter wheat in 2017 at the same experimental site (Fig. 4B), yielding similar results (Dunnett's method, $P \leq 0,028$ ). In 2017, the disease pressure differed (2015 versus 2017: Dunn's method, $P \leq$ $0.033)$. However, Rrha $\mathrm{Ef}$ significantly reduced brown rust symptoms in flag leaves (Dunnett's method, $P \leq 0.028$ ), especially with the higher dosage of $800 \mathrm{~g} \mathrm{ha}^{-1}$ (approximately 20\% disease severity). Although fenpropimorph at $94 \mathrm{~g} \mathrm{ha}^{-1}$ achieved less control of brown rust (an average of $33 \%$ inhibition), combined treatments with Rrha $a_{E f}$ and Corbel inhibited the emergence of brown rust by an average of $70 \%$. Through combined applications, significantly increased brown


Rrha $_{E f}$; Dunn's method, $\left.P<0.001\right)$, even at lower fungicide dosages.

$R$. rhabarbarum extract $\mathrm{Rrha}_{\mathrm{E}}$ induces resistance mechanisms in Arabidopsis. In order to discriminate between direct antifungal and local acquired resistance- or SAR-inducing effects of Rrha an Arabidopsis mutant screening was performed with mutants that were deficient in accumulating or responding to key regulators within induced resistance (IR) signaling. These plants were inoculated with E. cruciferarum at 1.2 spores $/ \mathrm{mm}^{2}$. By studying the efficacy of $0.5 \% \mathrm{Rrha}_{\mathrm{E}}$ in protecting Arabidopsis from disease, indications for appropriately activated host resistance pathways were detected in the case of the SA-impaired mutant eds5-1. The disease

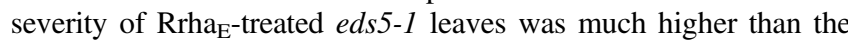
level in Col-8 plants (Dunn's method, $P<0.001$; Fig. 5A and B). This pointed to an SA-dependent type of resistance induced by Rrha $_{\mathrm{E}}$. LSAs with Rrha $\mathrm{E}_{\mathrm{E}}$ fractions 2 and $5(0.1 \%)$ as well as with standard compounds ECG and RES (0.1\%) showed (Fig. 5A and B) that the observed IR activation is related to stilbene agents (fraction 5 or RES; 73 to $88 \%$ disease severity versus control in the case of $e d s 5-1$ ).

To survey the possibility of priming effects that are solely due to extract treatment, Arabidopsis Col-8 plants were sprayed with a $0.1 \%$ Rrha $_{\mathrm{E}}$ solution and sampled at 3 and 9 HAT for transcript abundance analyses using Affymetrix DNA-microarray technology and qRT-PCR. Microarray data showed various upregulated gene transcripts (up to a 16.90-fold in both tests) with a clear relationship to genes involved in pathogen-resistance mechanisms (Supplementary Table S3). Among the genes considered were those which fit categories for incompatible interaction (response to accumulation of hydrogen peroxide [oxidative burst]), signal transduction (e.g., WRKY transcription factors), mitogen-activated protein kinase cascades, the phenylpropanoid metabolism (e.g., phenylalanine ammonia lyase), as well as SAR-related genes. Upregulated transcripts involved in cell wall fortification (lignin metabolic or biosynthetic process and callose deposition) could be linked to the rate of $B$. graminis $\mathrm{f}$. $\mathrm{sp}$. hordei papillae formation as part of the histochemical studies (Fig. $6 \mathrm{~A}, \mathrm{~B}$, and C). The B. graminis f. sp. hordei papillae formation rate was affected significantly by Rrha $\mathrm{E}_{\mathrm{E}}$ fractions 2 and 5 due to infection 
(Dunnett's method, $P<0.001$ ). As a result of the Rrhat treatment (microarray analyses), up to fivefold higher transcript abundances of the $P R$ genes $P R 1, P R 2$, and $P R 5$ were determined compared with the untreated controls. qRT-PCR analyses substantiated the microarray results and $P R$ transcript abundances were also significantly increased by extract treatment (Dunn's method versus control group $[0 \mathrm{H}], P \leq 0.022$ ) at $3 \mathrm{HAT}$ ( $\geq$ ninefold) and $9 \mathrm{HAT}$ ( $\geq$ fivefold) (Fig. 6D).

qRT-PCR was used to analyze $P R 1, P R 2$, and $P R 5$ transcript abundances after infection. For this purpose, Rrha $_{\mathrm{E}}$-treated Arabidopsis
Col-8 plants were inoculated with E. cruciferarum at 3.4 spores/ $\mathrm{mm}^{2}$ and sampled at 8 and 16 HAI. qRT-PCR analyses showed overall increased transcript abundances of these markers due to the Rrha treatment at the defined points in time after inoculation (Fig. 6E). Compared with uninfected but pretreated controls, significant differences could be detected at 8 and $16 \mathrm{HAI}$ ( $t$ test, $P \leq 0.005$ ). Although $P R 1$ and $P R 2$ transcript abundances decreased with time, induction of $P R 5$ was greatest at $16 \mathrm{HAI}(t$ test versus $48 \mathrm{HAT}, P<0.001$ ). With respect to all investigated $P R$ genes, no significant differences between treatment groups could be observed at 48 HAT $(t$ test,
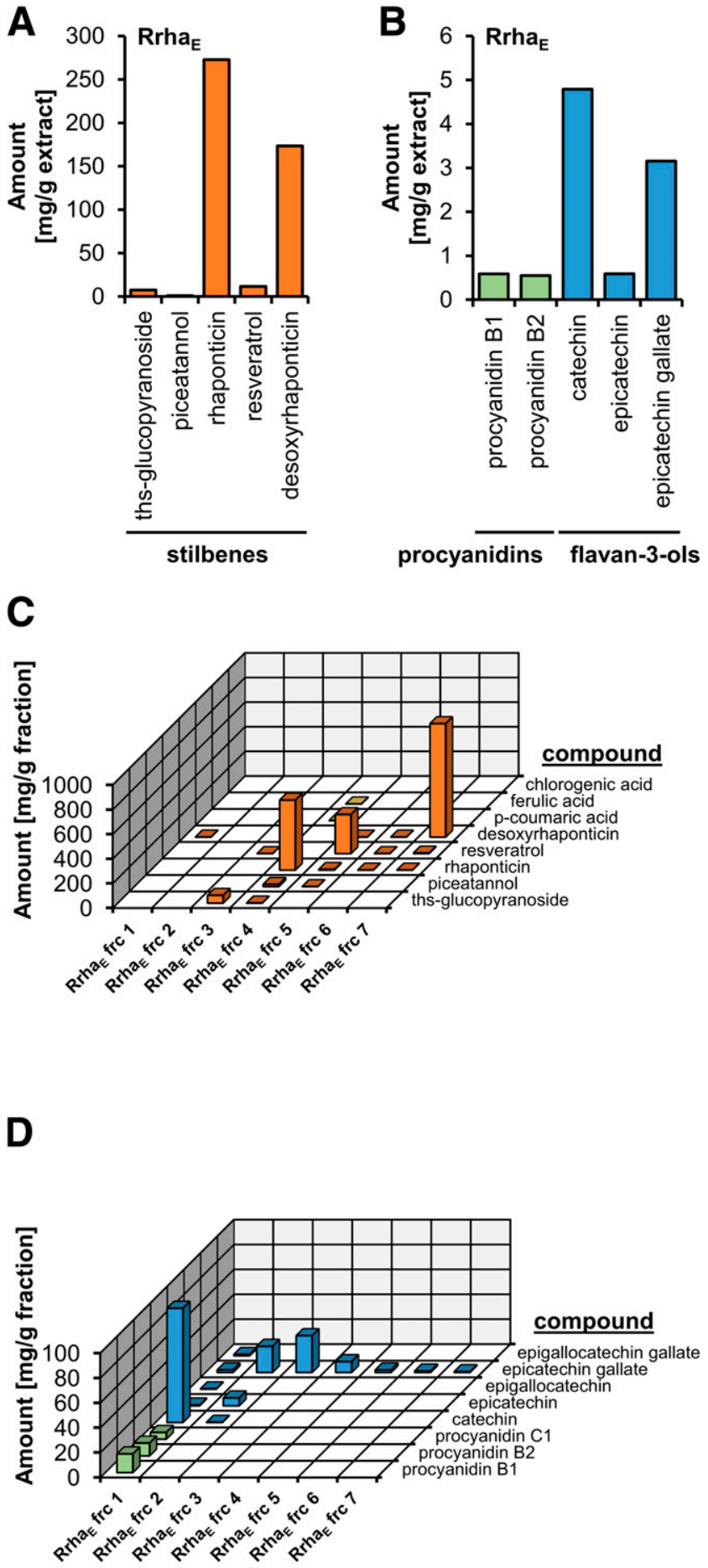

$\mathbf{E}$

resveratrol

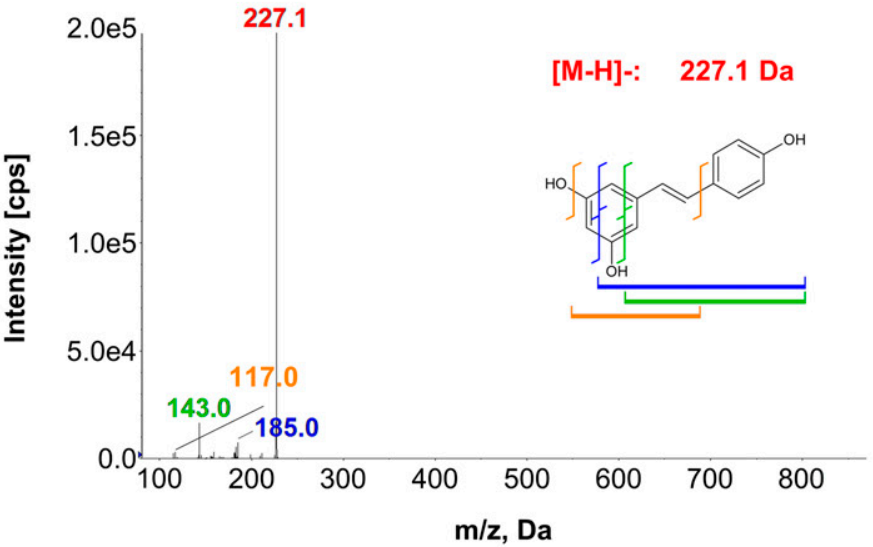

$\mathbf{F}$

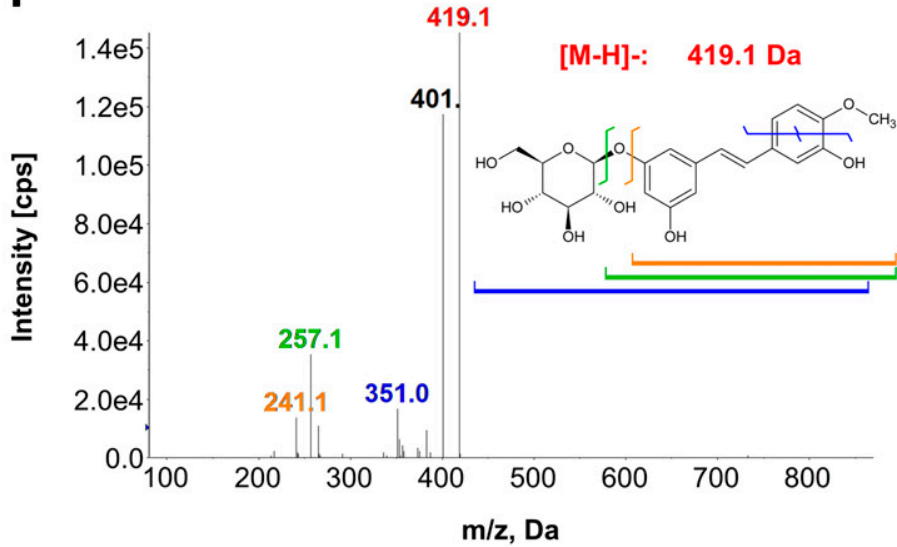

G

epicatechin gallate



Fig. 2. Liquid chromatography mass spectrometry (MS) analyses of polyphenols in Rheum rhabarbarum crude extract (Rrha $\mathrm{E}_{\mathrm{E}}$ ) and fractions of Rrha $\mathrm{E}_{\mathrm{E}}$ Quantification of $\mathbf{A}$, stilbenes and $\mathbf{B}$, procyanidins and flavan-3-ols in Rrha $;$; and $\mathbf{C}$ and D, fractions (frc) of Rrha $\mathrm{E}_{\mathrm{E}}$ Samples were measured in duplicate. 3,4',5-Trihydroxystilbene-3-0- $\beta$-D-glucopyranoside is abbreviated as ths-glucopyranoside. Representative MS spectra of E, resveratrol (RES); F, rhaponticin (RHA); and G, epicatechin gallate (ECG), identified by the main ion (marked in red) and several fragments (colored). 
$P=0.480,0.765$, and 0.617 for $P R 1, P R 2$, and $P R 5$, respectively; Fig. 6E).

\section{Discussion}

Rheum roots contain various bioactive flavonoids, stilbenes, and complex polyphenolic substances. The aim of this study was to investigate the potential of standardized Rheum root extracts that include these substances for controlling fungal and oomycete plant pathogens. In contrast to most studies, the investigated Rheum root extracts (i.e., Rrha $\mathrm{E}_{\mathrm{E}}$ ) were examined in experiments ranging from in vitro assays to large-scale field trials using different dosages, including chemical structure elucidation and the application of isolated single compounds. The data collectively showed that polyphenols from Rheum roots exhibited pronounced antifungal activity. Root extracts from Rheum such as Roff $\mathrm{E} 39_{9}$ and $\mathrm{Rrha}_{\mathrm{E}}$ clearly demonstrated protective disease-controlling effects against a wide range of necrotrophic, hemibiotrophic, and biotrophic phytopathogens that are agriculturally important. These included fungi (e.g., Fusarium spp. and A. brassicicola) and oomycetes (P. capsici) in vitro and, in particular, the fungus B. graminis f. sp. hordei in vivo, which also causes major crop losses (Dean et al. 2012; Ridout 2009). The data strongly suggested that reduced nutrient uptake by haustoria from plants treated with ECG and stilbenes may be responsible for the reduction in incidences of mildew disease. Rrha $\mathrm{E}_{\mathrm{E}}$, which was most effective against $B$. graminis $\mathrm{f}$. sp. hordei conidial germination as well as haustoria and pustule formation, also exhibited positive effects against the apple scab pathogen $V$. inaequalis, which can nowadays only be effectively controlled by high-efficacy fungicides (Cox 2015). The current study revealed substantially reduced disease severities in barley leaves infected with $B$. graminis f. sp. hordei as well as complete growth inhibition of $V$. inaequalis sustainable in vitro. Throughout Europe, the majority of apple cultivars is susceptible to scab and powdery mildew (Podosphaera leucotricha), which requires intensive fungicide applications that are known to have a negative ecological impact (Lespinasse et al. 2000) such as adverse effects to beneficial organisms (e.g., pollinators). Rice, on the other hand, is one of the fifth-largest cash crops and feeds one-third of the human population (Head 2017). In view of the strong effects


control ECG

control PRO B2 $\overline{\text { RHA }} \overline{\text { PRO B2 + RHA }}$

Fig. 3. Protective and synergistic effects of Rrha fractions and compounds typical for Rheum. A, Blumeria graminis f. sp. hordei (Bgh) pustule formation (pustules/leaf area) 2 weeks after Hordeum vulgare 'Lawina' infection. Three-week-old plants were sprayed with $250 \mathrm{ppm}$ concentrated fractions (frc) of Rheum rhabarbarum extract (Rrha $\mathrm{E}_{\mathrm{E}}$ followed by inoculation with B. graminis f. sp. hordei at $48 \mathrm{~h}$ after treatment (HAT). For controls, an equal volume of the solvent was sprayed. Significant differences in disease severity assessed using Dunnett's method $(P \leq 0.003)$ are marked with an asterisk. Graph bars represent mean values of 2 biological and 14 technical replicates; error bars represent standard deviation (SD). B, Conidial germination rate and C, haustoria formation rate of $B$. graminis f. sp. hordei 2 days after $H$. vulgare 'Lawina' infection. Two-week-old plants were sprayed with $250 \mathrm{ppm}$ Rrha fractions (frc) 2 and 5 and $125 \mathrm{ppm}$ of the standard compounds epicatechin gallate (ECG) and resveratrol (RES), followed by inoculation with B. graminis f. sp. hordei at 48 HAT. For controls, an equal volume of the solvent was sprayed. Significant differences in B. graminis f. sp. hordei germination rate assessed using Dunnett's method $(P \leq 0.020)$ and haustoria rate using $t$ test $(P \leq 0.031)$ are marked with an asterisk. Graph bars represent mean values of two biological and five technical replicates; error bars represent standard error of the mean. D and E, B. graminis f. sp. hordei pustule formation (pustules/leaf area) 3 weeks after $H$. vulgare 'Lawina' infection. Three-week-old plants were sprayed with the standard substances ECG and RES (D) as well as procyanidin B2 (PRO B2) and rhaponticin (RHA) (E) followed by inoculation with B. graminis f. sp. hordei at 48 HAT. For controls, an equal volume of the solvent was sprayed. Significant differences in disease severity assessed using Dunn's method versus control group $(P \leq 0.002)$ are marked with an asterisk. Graph bars represent mean values of two biological and $\geq$ nine technical replicates; error bars represent SD. Representative box values demonstrate synergisms obtained by comparing observed $\left(\mathrm{e}_{\mathrm{o}}\right)$ versus calculated $\left(\mathrm{e}_{\mathrm{c}}\right)$ efficiencies against $B$. graminis $\mathrm{f}$. $\mathrm{sp}$. hordei. 
against the rice blast fungus in vitro, defined Rheum root extracts with well-characterized ingredients may represent a promising prospect for developing chemical leads from these botanicals in future.

The profound in vivo B. graminis f. sp. hordei effects of various Rheum root extracts had a high probability of being accompanied by synergistic interactions between minor substances such as ECG, catechin, or PRO B1 or B2 (flavonoids) and major components such as RES, DRHA, or RHA (stilbene derivates), present in the crude extracts. The hypothesis that heterogeneous polyphenols are bioactive compounds that inhibit $B$. graminis f. sp. hordei pustule formation was supported by the barley LSAs with various standard substances typical for Rheum (Supplementary Fig. S3). Except for a comprehensive description of polyphenols typical for Rheum spp., such synergisms against $B$. graminis f. sp. hordei pustule formation have not been described before. Interestingly, the Rrha ${ }_{E}$ fractions which actively prevented B. graminis f. sp. hordei pustule formation in barley LSAs contained galloylated (ECG in fraction 2) and hydroxylated (catechin and PRO B1 in fraction 1) flavonoids as well as hydroxylated (RES in fraction 5), glucosylated (RHA and DRHA in fractions 4 and 7; ths-glucoside in fraction 2), and galloylated (rhaponticin gallate in fraction 5) stilbenes. Flavonoid-dominated $\mathrm{Rrha}_{\mathrm{E}}$ fraction 1 and stilbene fraction 5 were also validated by LSAs using tomato leaves infected with Phytophthora capsici isolate LT263. The results correlated with large amounts of galloylated (e.g., ECG) and hydroxylated compounds, especially RES in fraction 5 (unpublished). The antifungal activity of gallic acid (e.g., reduced spore germination) was already demonstrated by Dix (1979) and Nguyen et al. (2013). The same applies to the antimicrobial and resistanceinducing potentials of flavonoids (Chakraborty and Chakraborti 2010; Hirasawa and Takada 2004; Tao et al. 2010) and stilbenes in general (Hart 1981; Kumar and Nambisan 2014; Pociecha et al. 2014; Sergent at al. 2014). The results presented here demonstrate the multiconstituent-based antifungal potential of these Rheum root extracts, with the advantage of low risks for the development of pathogen resistance. Importantly, the content of anthraquinones in the crude extracts could be sharply reduced by using petroleum benzine
A

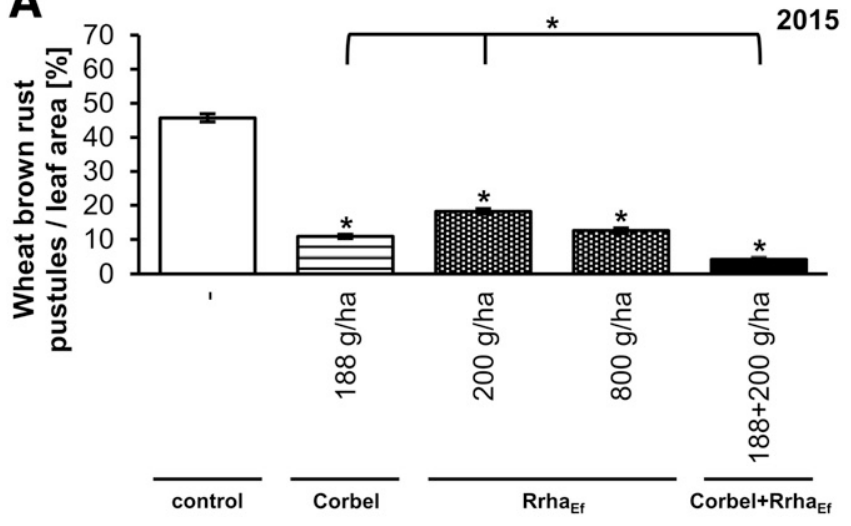

B

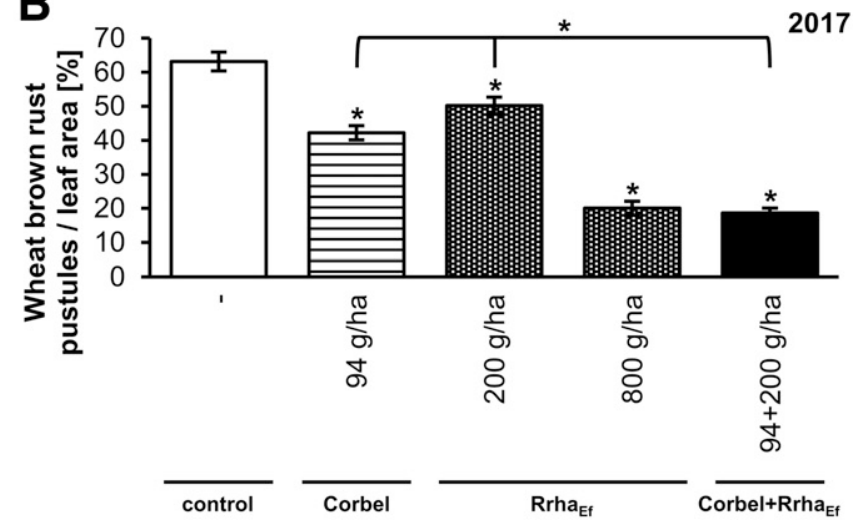

Fig. 4. Effects of Rheum rhabarbarum root extract in field trials. Brown rust pustule formation (pustules/leaf area) in infected plots of Triticum aestivum A, 'Pamier' and B, 'Julie E' (flag leaves) of a field trial in 2015 (A) and the experimental repeat in 2017 (B). Plants were sprayed with formulated $R$. rhabarbarum extract (Rrha $\mathrm{EF}_{\mathrm{Ef}}$ ) and the chemical Corbel. For controls, an equal volume of the solvent was sprayed. Significant differences in disease severity assessed using Dunnett's method $(P<0.001$ and $\leq 0.028$ for $A$ and $B$, respectively) are marked with an asterisk. Brackets symbolize significant differences in disease severity among the treatment groups of individual and combined applications (Dunn's method, $P<0.001$ ). Graph bars represent mean values of $700(A)$ and $150(B)$ technical replicates per treatment group; error bars represent standard error of the mean.

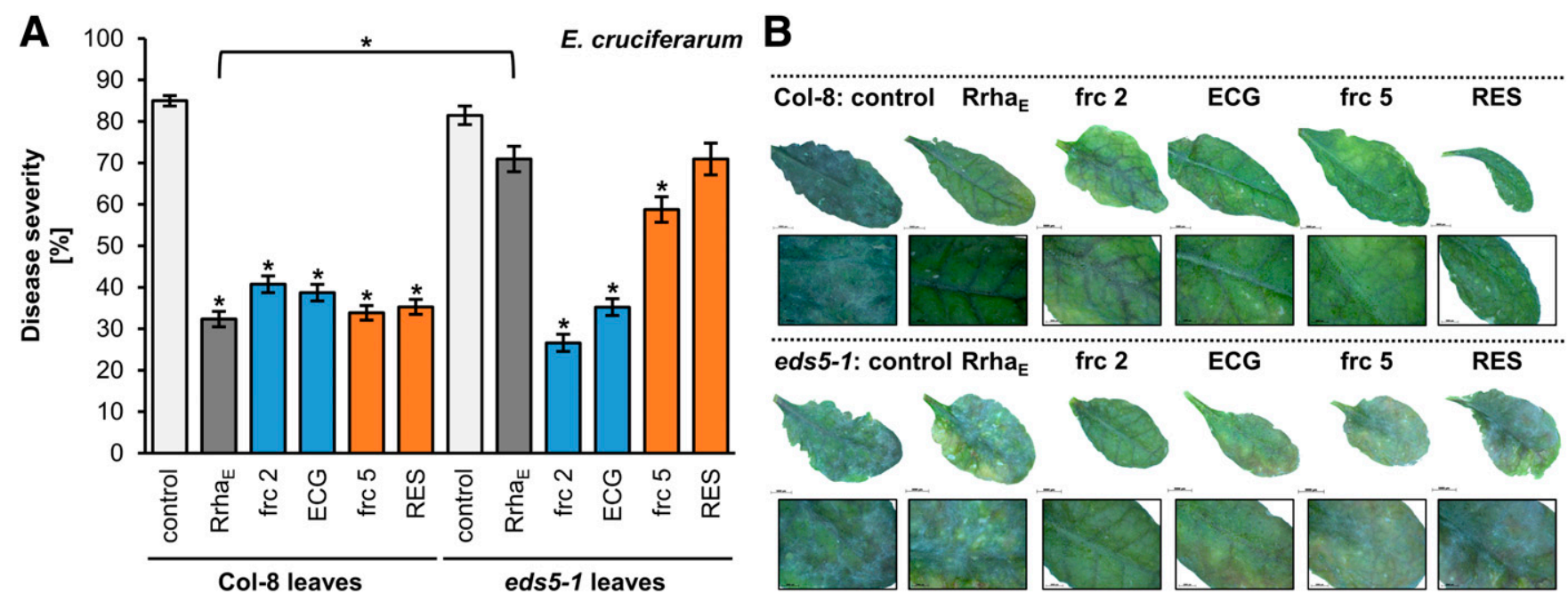

Fig. 5. Effects of Rheum rhabarbarum crude extract and fractions in Arabidopsis. A, Erysiphe cruciferarum pustule formation (disease severity) 1 week after Arabidopsis thaliana Col-8 and eds5-1 infection. Eight-week-old plants were sprayed with $0.5 \%$ concentrated $R$. rhabarbarum extract (Rrha $\mathrm{E}_{\mathrm{E}}$ ), $0.1 \%$ Rrha $\mathrm{E}$ fractions (frc) 2 and 5 , and $0.1 \%$ of the standard compounds epicatechin gallate (ECG) and resveratrol (RES) followed by inoculation with $E$. cruciferarum at $48 \mathrm{~h}$ after treatment (HAT). For controls, an equal volume of the solvent was sprayed. Significant differences in infestation intensity assessed using Dunn's method versus control group $(P<0.001)$ are marked with an asterisk. Bracket symbolizes the significant difference in infestation intensity among the Rrha $\mathrm{E}_{\mathrm{E}}$ treatment groups (Dunn's method, $P<0.001$ ). Graph bars represent mean values of $\geq 3$ biological and 16 technical replicates; error bars represent standard error of the mean. B, Images show healthy mycelial growth with dense networks of secondary hyphae in solvent-treated as well as Rrha -treated (eds5-1) and stilbene (frc 5 and RES)-treated (eds5-1) leaves. Less intense and nonvital fungal growth was visible in leaves treated with flavan-3-ols (frc 2 and ECG; $\times 6.3$ and ×16 magnification, respectively). 
in the extraction process and preparative HPLC for fractionation, because anthraquinones may no longer be used in plant protection products in the EU (notified under document number C(2008) 8133).

The antifungal effects of Rrha $\mathrm{E}_{\mathrm{E}}$ were also intense in field trials against brown rust in wheat. This could be achieved by a maximum of two sprayings per season. In addition, no phytotoxic side effects were observed for dosages up to $800 \mathrm{~g} \mathrm{ha}^{-1}$. In combined use with the chemical fungicide Corbel, the efficacy of Corbel (and Rrha $a_{E}$ ) was significantly improved. In combination with systemically active Corbel, which accelerates the plant uptake of combined agents, Rrha $_{E}$ or mixed formulations can substantially contribute to a reduced spray rate of chemicals against brown rust in wheat, increased plant protection over single compounds, and, thus, the development of fungicides with a lower resistance risk.

Arabidopsis LSAs with the SA-deficient mutant eds5-1 (Nawrath et al. 2002) showed that the effect of Rrha ${ }_{E}$ on mildew appears to be SA dependent. SA correlates with local and systemic expression of PR protein-coding genes and is known to be the signal molecule of
SAR (Fu and Dong 2013; Gaffney et al. 1993; van Loon 1999; van Loon et al. 2006; Vlot et al. 2009). According to Chen et al. (2017), mutant $e d s 5-1$ is SAR deficient and impaired in the accumulation of SA and PRl-transcripts (Ferrari et al. 2003; Lu 2009; Nawrath et al. 2002). In the current study, qRT-PCR with Col-8 demonstrated that there were significantly higher transcript abundances of the $P R$ genes $P R 1, P R 2$, and $P R 5$ after treatment and after infection. This hints at a priming effect of $R_{r h a}$, which was confirmed by DNA-microarray analyses displaying several upregulated SARrelated genes. IR is known to be associated with plant cell priming (Beckers et al. 2009; Kohler et al. 2002), which causes responsiveness and greater sensitivity when there is a pathogen attack (Conrath et al. 2002, 2006, 2015). The higher $\beta$-1,3-glucanase 3 gene transcription as a result of the Rrha $\mathrm{E}_{\mathrm{E}}$ treatment as well as the significant postinfection transcript abundance of $P R 2$ suggests that Rrha $\mathrm{E}_{\mathrm{E}}$ possibly acts as an elicitor of plant defense responses similar to $\beta-1,3-$ glucan or chitin oligomers of fungal cell walls (Cosio et al. 1996; Klarzynski et al. 2000; Oliveira-Garcia and Deising 2013; Shetty
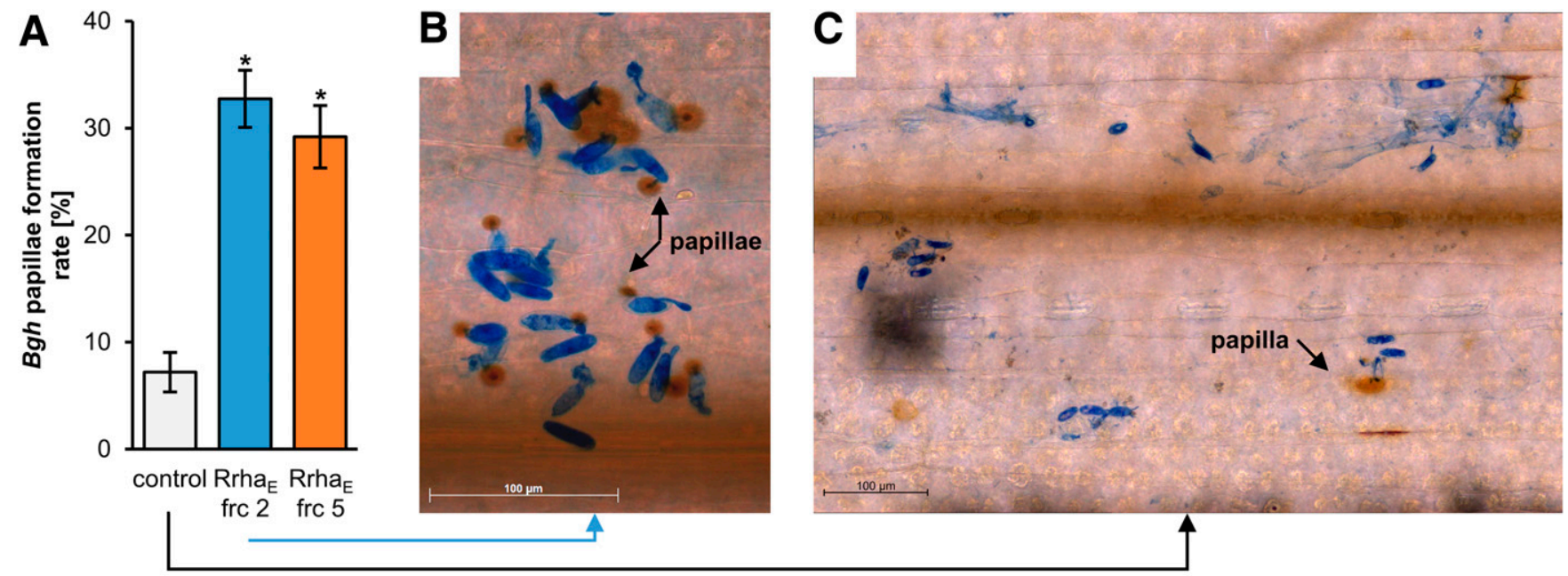

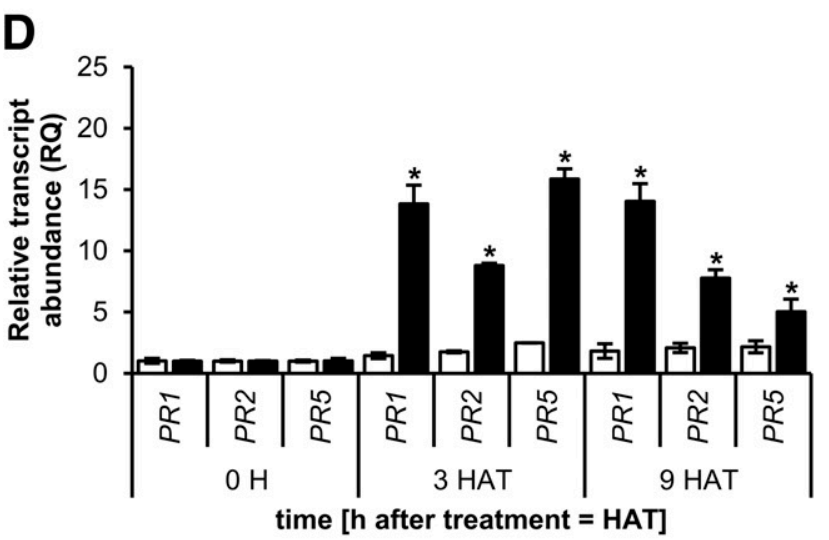

口control $\mathbf{a r h a} \mathrm{R}_{\mathrm{E}}$
E



time [h after inoculation $=\mathrm{HAl}]$

\section{口control $\square$ Rrha $_{E}$}

Fig. 6. Defense-related formations in barley and transcript abundances of defense-related genes in Arabidopsis activated by Rheum rhabarbarum root extract Rrha $\mathrm{E}_{\mathrm{E}}$. A, Papillae formation rate of Blumeria graminis f. sp. hordei (Bgh) 2 days after Hordeum vulgare 'Lawina' infection. Two-week-old plants were sprayed with $R$. rhabarbarum extract (Rrha $\mathrm{E}$ ) fractions (frc) 2 and $5(250 \mathrm{ppm})$ followed by inoculation with $B$. graminis $\mathrm{f}$. sp. hordei $48 \mathrm{~h}$ after Lawina treatment. For controls, an equal volume of the solvent was sprayed. Significant differences in papillae appearance assessed using Dunnett's method $(P<0.001)$ are marked with an asterisk. Flavan-3-ol frc 2 and stilbene frc 5 did not differ ( $t$ test, $P=0.381$ ). Graph bars represent mean values of two biological and five technical replicates; error bars represent standard error of the mean (SEM). B and $\mathbf{C}$, Microscopy images show papillae in a representative leaf treated with frc 2 main compound epicatechin gallate (pure standard) $72 \mathrm{~h}$ after Lawina infection ( $\times 400$ magnification) as a phenotypical result of activated defense-related genes (B) compared with the respective control (C). D and $\mathbf{E}$, Relative transcript abundances (relative quantification) of $P R 1, P R 2$, and PR5 3 and $9 \mathrm{~h}$ after treatment (HAT) with Arabidopsis thaliana Col-8 (D) as well as 8 and $16 \mathrm{~h}$ after infection (HAl) of Col-8 with Erysiphe cruciferarum $(E)$ detected by quantitative reverse-transcription polymerase chain reaction. Eight-week-old plants were sprayed with $0.1 \%$ concentrated Rrha $a_{E}$ followed by leaf sampling at 3 and $9 \mathrm{HAT}$ (D) or inoculation with E. cruciferarum at $48 \mathrm{HAT}$ and leaf sampling at 8 and $16 \mathrm{HAl}(\mathrm{E})$. For controls, an equal volume of the solvent was sprayed. The reference gene At-Ubiquitin was used for normalization. In D, significant differences in transcript abundance assessed using Dunn's method versus control group ( $0 \mathrm{H}$; $P \leq 0.022)$ are marked with an asterisk. Differences in transcript abundance versus $\mathrm{H}_{2} \mathrm{O}$ group (control) were assessed by $t$ test $(P \leq 0.012)$. In $\mathrm{E}$, significant differences in transcript abundance assessed using $t$ test (48 HAT; $P \leq 0.005$ ) are marked with an asterisk. Differences in transcript abundance versus $\mathrm{H}_{2} \mathrm{O}$ group (control) were assessed by $t$ test $(P \leq 0.040)$. Graph bars represent mean values of two biological and $\geq$ three technical replicates; error bars represent standard deviation (D) or SEM (E). 
et al. 2009). van Loon and van Strien (1999) have reported that the expression of $P R 1, P R 2$, and $P R 5$ is required for defense responses against the biotrophic Hyaloperonospora parasitica in Arabidopsis and that the PR-1 family is a marker for SAR. In the current study, the polyphenolic agents of $\mathrm{Rrha}_{\mathrm{E}}$ may induce an SA-triggered SAR in Arabidopsis, primarily due to stilbene agents.

Therefore, it is possible that the protective effects of Rrha $\mathrm{E}_{\mathrm{E}}$ depend not only on its direct antifungal activity but also on its induction of SAR. According to Conrath et al. (2015), various natural and synthetic substances can be used in chemical defense priming, some of which are included in agricultural plant protection products (e.g., SA or BTH). However, several crops display a reduced tolerance to SA, which is economically disadvantageous (Ryals et al. 1996). The application of Rrha ${ }_{E}$ might close this gap because tolerance reduction has yet to be observed. In view of the disadvantages of pure plant activators (plant energy expenditure) or curative fungicides (risk of resistance), polyphenols from the Rheum spp. could be a valuable alternative in crop protection against plant-pathogenic fungi and oomycetes. Our future goals include collaborations with crop science companies to economically exploit the new extraction technology and antifungal formulations that include synergistically acting ingredients and innovative adjuvants.

\section{Acknowledgments}

We thank J. Imani and E. Stein, University of Giessen, Department of Phytopathology, for providing E. cruciferarum, B. graminis f. sp. hordei, and the Fusarium spp.; J. Steinbach, Carl Zeiss Microscopy GmbH, Jena, for enabling high quality images using the Stemi 508 stereomicroscope; and C. Stratmann and HELM AG, Hamburg, for their support in the formulation of Rrha $\mathrm{E}$.

\section{Literature Cited}

Adrian, M., Jeandet, P., Veneau, J., Weston, L. A., and Bessis, R. 1997. Biological activity of resveratrol, a stilbenic compound from grapevines, against Botrytis cinerea, the causal agent for gray mold. J. Chem. Ecol. 23:1689-1702.

Agarwal, S. K., Singh, S. S., Verma, S., and Kumar, S. 2000. Antifungal activity of anthraquinone derivatives from Rheum emodi. J. Ethnopharmacol. 72:43-46.

Ammar, G. A., Tryono, R., Döll, K., Karlovsky, P., Deising, H. B., and Wirsel, S. G. R. 2013. Identification of ABC transporter genes of Fusarium graminearum with roles in azole tolerance and/or virulence. PLoS One 8: e79042.

Aznar, A., Chen, N. W. G., Thomine, S., and Dellagi, A. 2015. Immunity to plant pathogens and iron homeostasis. Plant Sci. 240:90-97.

Baltruschat, H., Kabrodt, K., and Schellenberg, I., and Anhalt University of Applied Sciences. 2013. Antifungal formulations for combatting plant diseases. World Intellectual Property Organization patent WO2013110258A1.

Beckers, G. J. M., and Conrath, U. 2007. Priming for stress resistance: From the lab to the field. Curr. Opin. Plant Biol. 10:425-431.

Beckers, G. J. M., Jaskiewicz, M., Liu, Y., Underwood, W. R., He, S. Y., Zhang, S., and Conrath, U. 2009. Mitogen-activated protein kinases 3 and 6 are required for full priming of stress responses in Arabidopsis thaliana. Plant Cell 21:944-953.

Cáceres, A., Cabrera, O., Morales, O., Mollinedo, P., and Mendia, P. 1991. Pharmacological properties of Moringa oleifera. 1: Preliminary screening for antimicrobial activity. J. Ethnopharmacol. 33:213-216.

Chakraborty, D., and Chakraborti, S. 2010. Bioassay-guided isolation and identification of antibacterial and antifungal component from methanolic extract of green tea leaves (Camellia sinensis). Res. J. Phytochem. 4:78-86.

Chapman, P. 2014. Is the regulatory regime for the registration of plant protection products in the EU potentially compromising food security? Food Energy Secur. 3:1-6.

Chen, H., Chen, J., Li, M., Chang, M., Xu, K., Shang, Z., Zhao, Y., Palmer, I., Zhang, Y., McGill, J., Alfano, J. R., Nishimura, M. T., Liu, F., and Fu, Z. Q. 2017. A bacterial type III effector targets the master regulator of salicylic acid signaling, NPR1, to subvert plant immunity. Cell Host Microbe 22: 777-788.e7.

Chen, J., and Dai, G. H. 2014. Effect of d-pinitol isolated and identified from Robinia pseudoacacia against cucumber powdery mildew. Sci. Hortic. (Amsterdam) 176:38-44.

Choi, G. J., Lee, S. W., Jang, K. S., Kim, J. S., Cho, K. Y., and Kim, J. C. 2004. Effects of chrysophanol, parietin, and nepodin of Rumex crispus on barley and cucumber powdery mildews. Crop Prot. 23:1215-1221.

Chollet, J. F., Couderchet, M., and Bonnemain, J. L. 2014. Crop protection: New strategies for sustainable development. Environ. Sci. Pollut. Res. 21:4793-4796.

Colby, S. R. 1967. Calculating synergistic and antagonistic responses of herbicide combinations. Weeds 15:20-22.

Conrath, U. 2006. Systemic acquired resistance. Plant Signal. Behav. 1:179-184.

Conrath, U., Beckers, G. J. M., Flors, V., García-Agustín, P., Jakab, G., Mauch, F., Newman, M. A., Pieterse, C. M. J., Poinssot, B., Pozo, M. J., Pugin, A.,
Schaffrath, U., Ton, J., Wendehenne, D., Zimmerli, L., and Mauch-Mani, B. 2006. Priming: Getting ready for battle. Mol. Plant-Microbe Interact. 19: 1062-1071.

Conrath, U., Beckers, G. J. M., Langenbach, C. J. G., and Jaskiewicz, M. R. 2015. Priming for enhanced defense. Annu. Rev. Phytopathol. 53:97-119.

Conrath, U., Pieterse, C. M. J., and Mauch-Mani, B. 2002. Priming in plantpathogen interactions. Trends Plant Sci. 7:210-216.

Copping, L. G., and Menn, J. J. 2000. Biopesticides: A review of their action, applications and efficacy. Pest Manage. Sci. 56:651-676.

Cosio, E. G., Feger, M., Miller, C. J., Antelo, L., and Ebel, J. 1996. High-affinity binding of fungal $\beta$-glucan elicitors to cell membranes of species of the plant family Fabaceae. Planta 200:92-99.

Cox, K. D. 2015. Fungicide resistance in Venturia inaequalis, the causal agent of apple scab, in the United States. Pages 433-447 in: Fungicide Resistance in Plant Pathogens. H. Ishii and D. W. Hollomon, eds. Springer, Tokyo, Japan.

Dean, R., van Kan, J. A. L., Pretorius, Z. A., Hammond-Kosack, K. E., di Pietro, A., Spanu, P. D., Rudd, J. J., Dickman, M., Kahmann, R., Ellis, J., and Foster, G. D. 2012. The top 10 fungal pathogens in molecular plant pathology. Mol. Plant Pathol. 13:414-430.

Deising, H. B., Gase, I., and Kubo, Y. 2017. The unpredictable risk imposed by microbial secondary metabolites: How safe is biological control of plant diseases? J. Plant Dis. Prot. 124:413-419.

Dix, N. J. 1979. Inhibition of fungi by gallic acid in relation to growth on leaves and litter. Trans. Br. Mycol. Soc. 73:329-336.

Dong, X. 1998. SA, JA, ethylene, and disease resistance in plants. Curr. Opin. Plant Biol. 1:316-323.

Ferrari, S., Plotnikova, J. M., De Lorenzo, G., and Ausubel, F. M. 2003. Arabidopsis local resistance to Botrytis cinerea involves salicylic acid and camalexin and requires EDS4 and PAD2, but not SID2, EDS5 or PAD4. Plant J. 35:193-205.

Fu, Z. Q., and Dong, X. 2013. Systemic acquired resistance: Turning local infection into global defense. Annu. Rev. Plant Biol. 64:839-863.

Gaffney, T., Friedrich, L., Vernooij, B., Negrotto, D., Nye, G., Uknes, S., Ward, E., Kessmann, H., and Ryals, J. 1993. Requirement of salicylic acid for the induction of systemic acquired resistance. Science 261:754-756.

Gonzalez Ureña, A., Orea, J. M., Montero, C., Jiménez, J. B., González, J. L., Sánchez, A., and Dorado, M. 2003. Improving postharvest resistance in fruits by external application of trans-resveratrol. J. Agric. Food Chem. 51:82-89.

Görlach, J., Volrath, S., Knauf-Beiter, G., Hengy, G., Beckhove, U., Kogel, K. H., Oostendorp, M., Staub, T., Ward, E., Kessmann, H., and Ryals, J. 1996. Benzothiadiazole, a novel class of inducers of systemic acquired resistance, activates gene expression and disease resistance in wheat. Plant Cell 8:629-643.

Gozzo, F., and Faoro, F. 2013. Systemic acquired resistance (50 years after discovery): Moving from the lab to the field. J. Agric. Food Chem. 61: 12473-12491.

Hahn, M. 2014. The rising threat of fungicide resistance in plant pathogenic fungi: Botrytis as a case study. J. Chem. Biol. 7:133-141.

Hain, R., Reif, H. J., Krause, E., Langebartels, R., Kindl, H., Vornam, B., Wiese, W., Schmelzer, E., Schreier, P. H., Stöcker, R. H., and Stenzel, K. 1993. Disease resistance results from foreign phytoalexin expression in a novel plant. Nature 361:153-156.

Harborne, J. B., and Williams, C. A. 2000. Advances in flavonoid research since 1992. Phytochemistry 55:481-504.

Hart, J. H. 1981. Role of phytostilbenes in decay and disease resistance. Annu. Rev. Phytopathol. 19:437-458.

Head, J. W. 2017. International Law and Agroecological Husbandry: Building Legal Foundations for a New Agriculture. Routledge, New York, NY, U.S.A.

Herger, G., and Klingauf, F. 1990. Control of powdery mildew fungi with extracts of the giant knotweed, Reynoutria sachalinensis (Polygonaceae). Meded. Fac. Landbouwwet. Rijksuniv. Gent 55:1007-1014.

Hermann, M., Maier, F., Masroor, A., Hirth, S., Pfitzner, A. J. P., and Pfitzner, U. M. 2013. The Arabidopsis NIMIN proteins affect NPR1 differentially. Front. Plant Sci. 4:88

Herms, S., Seehaus, K., Koehle, H., and Conrath, U. 2002. A strobilurin fungicide enhances the resistance of tobacco against tobacco mosaic virus and Pseudomonas syringae pv tabaci. Plant Physiol. 130:120-127.

Hirasawa, M., and Takada, K. 2004. Multiple effects of green tea catechin on the antifungal activity of antimycotics against Candida albicans. J. Antimicrob. Chemother. 53:225-229.

Hollomon, D. W. 2015. Fungicide resistance: 40 years on and still a major problem. Pages 3-11 in: Fungicide Resistance in Plant Pathogens. Principles and a Guide to Practical Management. H. Ishii and D. W. Hollomon, eds. Springer, Tokyo, Japan

Hückelhoven, R., Fodor, J., Preis, C., and Kogel, K. H. 1999. Hypersensitive cell death and papilla formation in barley attacked by the powdery mildew fungus are associated with hydrogen peroxide but not with salicylic acid accumulation. Plant Physiol. 119:1251-1260.

Hückelhoven, R., and Kogel, K. H. 1998. Tissue-specific superoxide generation at interaction sites in resistant and susceptible near-isogenic barley lines attacked by the powdery mildew fungus (Erysiphe graminis f. sp. hordei). Mol. PlantMicrobe Interact. 11:292-300.

Johansson, O. N., Fahlberg, P., Karimi, E., Nilsson, A. K., Ellerström, M., and Andersson, M. X. 2014. Redundancy among phospholipase D isoforms in 
resistance triggered by recognition of the Pseudomonas syringae effector AvrRpm1 in Arabidopsis thaliana. Front. Plant Sci. 5:639.

Kauss, H., Theisinger-Hinkel, E., Mindermann, R., and Conrath, U. 1992. Dichloroisonicotinic and salicylic acid, inducers of systemic acquired resistance, enhance fungal elicitor responses in parsley cells. Plant J. 2:655-660.

Kessmann, H., Staub, T., Hofman, C., Maetzke, T., Herzog, J., Ward, E., Uknes, S., and Ryals, J. 1994. Induction of systemic acquired disease resistance in plants by chemicals. Annu. Rev. Phytopathol. 32:439-459.

Kim, J. C., Choi, G. J., Lee, S. W., Kim, J. S., Chung, K. Y., and Cho, K. Y. 2004. Screening extracts of Achyranthes japonica and Rumex crispus for activity against various plant pathogenic fungi and control of powdery mildew. Pest Manage. Sci. 60:803-808.

Kim, Y. S., Dixon, E. W., Vincelli, P., and Farman, M. L. 2003. Field resistance to strobilurin $\left(\mathrm{Q}_{0} \mathrm{I}\right)$ fungicides in Pyricularia grisea caused by mutations in the mitochondrial cytochrome b gene. Phytopathology 93:891-900.

Klarzynski, O., Plesse, B., Joubert, J. M., Yvin, J. C., Kopp, M., Kloareg, B., and Fritig, B. 2000. Linear $\beta-1,3$ glucans are elicitors of defense responses in tobacco. Plant Physiol. 124:1027-1038.

Koga, H., Bushnell, W. R., and Zeyen, R. J. 1990. Specificity of cell type and timing of events associated with papilla formation and the hypersensitive reaction in leaves of Hordeum vulgare attacked by Erysiphe graminis f. sp. hordei. Can. J. Bot. 68:2344-2352.

Kohler, A., Schwindling, S., and Conrath, U. 2002. Benzothiadiazole-induced priming for potentiated responses to pathogen infection, wounding, and infiltration of water into leaves requires the NPRI/NIMI gene in Arabidopsis. Plant Physiol. 128:1046-1056.

Konstantinidou-Doltsinis, S., and Schmitt, A. 1998. Impact of treatment with plant extracts from Reynoutria sachalinensis (F. Schmidt) Nakai on intensity of powdery mildew severity and yield in cucumber under high disease pressure. Crop Prot. 17:649-656.

Kuhl, J. C., and DeBoer, V. L. 2008. Genetic diversity of rhubarb cultivars. J. Am. Soc. Hortic. Sci. 133:587-592.

Kumar, S. N., and Nambisan, B. 2014. Antifungal activity of diketopiperazines and stilbenes against plant pathogenic fungi in vitro. Appl. Biochem. Biotechnol. 172:741-754.

Langcake, P., and Pryce, R. J. 1976. The production of resveratrol by Vitis vinifera and other members of the Vitaceae as a response to infection or injury. Physiol. Plant Pathol. 9:77-86.

Lawton, K., Uknes, S., Friedrich, L., Gaffney, T., Alexander, D., Goodman, R., Métraux, J. P., Kessmann, H., Ahl-Goy, P., Gut Rella, M., Ward, E., and Ryals, J. 1993. The molecular biology of systemic acquired resistance. Pages 422-432 in: Mechanisms of Plant Defense Responses. B. Fritig and M. Legrand, eds. Springer, Dordrecht, The Netherlands.

Leadbeater, A. 2015. Recent developments and challenges in chemical disease control. Plant Prot. Sci. 51:163-169.

Lesemann, S. S., Schimpke, S., Dunemann, F., and Deising, H. B. 2006. Mitochondrial heteroplasmy for the cytochrome $b$ gene controls the level of strobilurin resistance in the apple powdery mildew fungus Podosphaera leucotricha (Ell. \& Ev.) E. S. Salmon. J. Plant Dis. Prot. 113:259-266.

Lespinasse, Y., Durel, C. E., Laurens, F., Parisi, L., Chevalier, M., and Pinet, C. 2000. A European project: D.A.R.E. - Durable apple resistance in Europe (FAIR5 CT97-3898) durable resistance of apple to scab and powderymildew: One step more towards an environmental friendly orchard. Acta Hortic. 538:197-200.

Lindermayr, C., Sell, S., Müller, B., Leister, D., and Durner, J. 2010. Redox regulation of the NPR1-TGA1 system of Arabidopsis thaliana by nitric oxide. Plant Cell 22:2894-2907.

Livak, K. J., and Schmittgen, T. D. 2001. Analysis of relative gene expression data

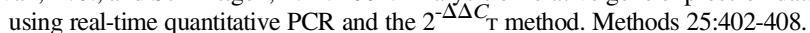

Lu, H. 2009. Dissection of salicylic acid-mediated defense signaling networks. Plant Signal. Behav. 4:713-717.

Malamy, J., and Klessig, D. F. 1992. Salicylic acid and plant disease resistance. Plant J. 2:643-654

Morris, S. W., Vernooij, B., Titatarn, S., Starrett, M., Thomas, S., Wiltse, C. C., Frederiksen, R. A., Bhandhufalck, A., Hulbert, S., and Uknes, S. 1998. Induced resistance responses in maize. Mol. Plant-Microbe Interact. 11: 643-658.

Nawrath, C., Heck, S., Parinthawong, N., and Métraux, J. P. 2002. EDS5, an essential component of salicylic acid-dependent signaling for disease resistance in Arabidopsis, is a member of the MATE transporter family. Plant Cell 14:275-286.

Nguyen, D. M. C., Seo, D. J., Lee, H. B., Kim, I. S., Kim, K. Y., Park, R. D., and Jung, W. J. 2013. Antifungal activity of gallic acid purified from Terminalia nigrovenulosa bark against Fusarium solani. Microb. Pathog. 56:8-15.

Oliveira-Garcia, E., and Deising, H. B. 2013. Infection structure-specific expression of $\beta$-1,3-glucan synthase is essential for pathogenicity of Colletotrichum graminicola and evasion of $\beta$-glucan-triggered immunity in maize. Plant Cell 25:2356-2378.
Pedras, M. S. C., and Ahiahonu, P. W. K. 2005. Metabolism and detoxification of phytoalexins and analogues by phytopathogenic fungi. Phytochemistry 66:391-411.

Pezet, R., Gindro, K., Viret, O., and Richter, H. 2004a. Effects of resveratrol, viniferins and pterostilbene on Plasmopara viticola zoospore mobility and disease development. Vitis 43:145-148.

Pezet, R., Gindro, K., Viret, O., and Spring, J. L. 2004b. Glycosylation and oxidative dimerization of resveratrol are respectively associated to sensitivity and resistance of grapevine cultivars to downy mildew. Physiol. Mol. Plant Pathol. 65:297-303.

Pociecha, E., Janeczko, Z., and Janeczko, A. 2014. Resveratrol stimulates phenolic metabolism and PSII efficiency in wheat infected with powdery mildew. J. Plant Interact. 9:494-503.

Ridout, C. J. 2009. Profiles in pathogenesis and mutualism: Powdery mildews Pages 51-68 in: Plant Relationships. The Mycota V. H. B. Deising, ed Springer, Berlin, Heidelberg, Germany.

Rupp, S., Plesken, C., Rumsey, S., Dowling, M., Schnabel, G., Weber, R. W. S., and Hahn, M. 2017. Botrytis fragariae, a new species causing gray mold on strawberries, shows high frequencies of specific and efflux-based fungicide resistance. Appl. Environ. Microbiol. 83:e00269-17.

Ryals, J. A., Neuenschwander, U. H., Willits, M. G., Molina, A., Steiner, H. Y., and Hunt, M. D. 1996. Systemic acquired resistance. Plant Cell 8:1809-1819.

Schneider, M., Schweizer, P., Meuwly, P., and Métraux, J. P. 1996. Systemic acquired resistance in plants. Int. Rev. Cytol. 168:303-340.

Sergent, T., Kohnen, S., Jourez, B., Beauve, C., Schneider, Y. J., and Vincke, C. 2014. Characterization of black locust (Robinia pseudoacacia L.) heartwood extractives: Identification of resveratrol and piceatannol. Wood Sci. Technol. 48:1005-1017.

Shetty, N. P., Jensen, J. D., Knudsen, A., Finnie, C., Geshi, N., Blennow, A., Collinge, D. B., and Jørgensen, H. J. L. 2009. Effects of $\beta$-1,3-glucan from Septoria tritici on structural defence responses in wheat. J. Exp. Bot. 60: 4287-4300.

Shi, Z., Zhang, Y., Maximova, S. N., and Guiltinan, M. J. 2013. TcNPR3 from Theobroma cacao functions as a repressor of the pathogen defense response. BMC Plant Biol. 13:204

Shine, M. B., Xiao, X., Kachroo, P., and Kachroo, A. 2019. Signaling mechanisms underlying systemic acquired resistance to microbial pathogens. Plant Sci. 279: 81-86.

Sierotzki, H., Wullschleger, J., and Gisi, U. 2000. Point mutation in cytochrome $b$ gene conferring resistance to strobilurin fungicides in Erysiphe graminis f. sp. tritici field isolates. Pestic. Biochem. Physiol. 68:107-112.

Stevenson, P. C., and Haware, M. P. 1999. Maackiain in Cicer bijugum Rech. f. associated with resistance to Botrytis grey mould. Biochem. Syst. Ecol. 27: 761-767.

Tao, S., Zhang, S., Tsao, R., Charles, M. T., Yang, R., and Khanizadeh, S. 2010. In vitro antifungal activity and mode of action of selected polyphenolic antioxidants on Botrytis cinerea. Arch. Phytopathol. PFL 43:1564-1578.

Thompson, G. D., Matten, S., Denholm, I., Whalon, M. E., and Leonard, P. 2008. The politics of resistance management: Working towards pesticide resistance management globally. Pages 146-165 in: Global Pesticide Resistance in Arthropods. M. E. Whalon, D. Mota-Sanchez, and R. M. Hollingworth, eds. CAB International, Wallingford, Oxfordshire, U.K

van Loon, L. C. 1999. Occurrence and properties of plant pathogenesis-related proteins. Pages 1-19 in: Pathogenesis-Related Proteins in Plants. S. K. Datta and S. Muthukrishnan, eds. CRC Press LLC, Boca Raton, FL, U.S.A.

van Loon, L. C., Rep, M., and Pieterse, C. M. J. 2006. Significance of inducible defense-related proteins in infected plants. Annu. Rev. Phytopathol. 44: 135-162.

van Loon, L. C., and van Strien, E. A. 1999. The families of pathogenesis-related proteins, their activities, and comparative analysis of PR-1 type proteins. Physiol. Mol. Plant Pathol. 55:85-97.

Vlot, A. C., Dempsey, D. A., and Klessig, D. F. 2009. Salicylic acid, a multifaceted hormone to combat disease. Annu. Rev. Phytopathol. 47:177-206.

Ward, E. R., Uknes, S. J., Williams, S. C., Dincher, S. S., Wiederhold, D. L., Alexander, D. C., Ahl-Goy, P., Métraux, J. P., and Ryals, J. A. 1991. Coordinate gene activity in response to agents that induce systemic acquired resistance. Plant Cell 3:1085-1094.

Yang, M., Duan, S., Mei, X., Huang, H., Chen, W., Liu, Y., Guo, C., Yang, T., Wei, W., Liu, X., He, X., Dong, Y., and Zhu, S. 2018. The Phytophthora cactorum genome provides insights into the adaptation to host defense compounds and fungicides. Sci. Rep. 8: Article 6534.

Yang, X., Ma, X., Yang, L., Yu, D., Qian, Y., and Ni, H. 2009. Efficacy of Rheum officinale liquid formulation on cucumber powdery mildew. Crop Prot. 28: 1031-1035.

Ye, M., Han, J., Chen, H., Zheng, J., and Guo, D. 2007. Analysis of phenolic compounds in rhubarbs using liquid chromatography coupled with electrospray ionization mass spectrometry. J. Am. Soc. Mass Spectrom. 18:82-91.

Yoon, M. Y., Cha, B., and Kim, J. C. 2013. Recent trends in studies on botanical fungicides in agriculture. Plant Pathol. J. 29:1-9. 